\title{
INDEKS KEPUASAN MASYARAKAT DESA KADUDAMPIT TERHADAP KINERJA PEMERINTAHAN DESA KADUDAMPIT
}

\author{
Muh. Aripin Nurmantoro ${ }^{1}$, Asep Saefullah Kamali
}

Sekolah Tinggi Keguruan dan Ilmu Pendidikan Al-Amin Indramayu ${ }^{1}$

STKIP Syekh Manshur²

Correspondence author: Asep Saefullah Kamali, email: asepsaefullahkamali@gmail.com

DOI: https://doi.org/10.37012/jipmht.v4i1.337

\begin{abstract}
ABSTRAK
Berdasarkan analisis yang dilakukan maka dapat disimpulkan kinerja pelayanan di Pemerintahan Desa Kadudampit Kecamatan Saketi Kabuapten Pandeglang dan Berdasarkan hasil perhitungan tersebut maka masing-masing bagian pada Pemerintahan Desa Kadudampit Kecamatan Saketi Kabuapten Pandeglang dapat di analisi dari 9 unsur yang dianalisi bahwa ada 3 Unsur yang dinilai kinerja unit pelayanan yang dianggap kurang baik oleh responden diantaranya, 1) Persyaratan Pelayanan nilai unsur pelayanannya baik tapi nilai intervalnya kurang, 2) waktu Pelayanan nilai unsur pelayanannya baik tapi nilai intervalnya rendah/kurang. 3) prilaku Pelaksana nilai unsur pelayanannya baik tapi nilai intervalnya rendah/kurang, 4) prosedur Pelayanan nilai unsur pelayanannya baik nilai intervalnya baik dan perlu dipertahankan dan ditingkatkan, 5) biaya /tarif nilai unsur pelayanannya baik nilai intervalnya baik dan perlu dipertahankan dan ditingkatkan, 6) produk sepesifikasi jenis layanan nilai unsur pelayanannya baik nilai intervalnya baik dan perlu dipertahankan dan ditingkatkan, 7) kompetensi Pelaksana nilai unsur pelayanannya baik nilai intervalnya baik dan perlu dipertahankan dan ditingkatkan, 8) maklumat Pelayanan nilai unsur pelayanannya baik nilai intervalnya baik dan perlu dipertahankan dan ditingkatkan, 9) penanganan dan pengaduan nilai unsur pelayanannya baik nilai intervalnya baik dan perlu dipertahankan dan ditingkatkan.
\end{abstract}

Kata kunci : indeks kepuasan masyarakat, pemerintah desa kadudampit.

\section{ABSTRACT}

Based on the analysis carried out, it can be concluded that the service performance in the Village Government of Kadudampit Village, Saketi District, Pandeglang Regency and Based on the results of these calculations, each section in the Village Government of Kadudampit Village, Saketi District, Pandeglang Regency can be analyzed from 9 elements analyzed that there are 3 elements that are assessed for performance. Service units that were considered unfavorable by the respondents included,

1) Service Requirements, the value of the service element was good, but the interval value was less, 2) The time of Service, the value of the service element was good, but the interval value was low / less. 3) the behavior of the implementer, the value of the service element is good but the interval value is low / less, 4) the service procedure, the value of the service element is good, the interval value is good and needs to be maintained and improved, 5) the cost / tariff value of the service element is good, the interval value is good and needs to be maintained and improved, 6) products specified for the type of service, the value of the service element is good, the interval value is good and needs to be maintained and improved, 7) the competence of the implementer, the value of the service element is good, the interval value is good and needs to be maintained and improved, 8) notice that the service element value is good, the interval value is good and needs to be maintained and improved, 9) handling and complaints on the value of the service elements are good at good intervals and need to be maintained and improved.

Keywords : community satisfaction index, village government kadudampit. 


\section{PENDAHULUAN}

Salah satu contoh bentuk pelayanan publik adalah penyelenggaraan pelayanan perizinan yang diberikan kepada masyarakat dalam hal pemenuhan kebutuhan dasar atas aspek legalitas suat perkara. Kegiatan penyelenggaraan pelayanan secara terpadu ini diharapkan dapat memberikan kontribusi yang positif bagi pengembangan kepercayaan masyarakat terhadap pelayanan yang diberikan oleh pemerintah.

Dalam mengukur sejauh mana kualitas pelayanan yang dapat diberikan kepada masyarakat, maka diperlukan suatu pedoman yang dapat mengukur terhadap kepercayaan masyarakat atas pelayanan yang diberikan pemerintah, untuk itulah diperlukan adanya suatu survey / kajian terhadap dampak pelayanan yang telah dirasakan oleh masyarakat. Hal ini sangat sesuai dengan Keputusan Menpan dan reformasi Birokrasi Nomor 16 Tahun 2014 tentang Pedoman survey kepuasan masyarakat terhadap penyelenggaraan pelayanan public.

Potensi ekonomi daerah tidak akan terlepas dari perkembangan arus globalisasi dan regionalisasi perekonomian. Dari arus globalisasi dan regonialisasi yang muncul selama ini akan berdampak baik maupun negatif pada perekonomian suatu daerah. Fenomena perekonomian yang demikian ini cenderung menuntut adanya peran aktif dari penyelenggara Pemerintah, baik di tingkat Pusat maupun Daerah untuk menjadikan kondisi tersebut bukan saja sebagai suatu "tantangan", Namun juga "kesempatan" bagi Daerah untuk mengambil prakarsa dan konsolidasi secara dini, bertahap, dan kelanjutan guna mengembangan Pemerintahan yang mampu mandiri dan terpercaya. Dengan kata lain pemerintah Daerah dituntut lebih banyak dalam menggali potensi ekonomi daerahnya, dan memainkan peranan yang besar dalam merangsang aktivitas ekonomi daerah untuk menigkatkan dan membina kemandirian keuangan daerah dalam pembiayaan penyelenggaraan Pemerintahan, pembangunan, dan pelayanan kepada masyarakat.

\section{METODE PELAKSANAAN}

Penelitian dapat digolongkan menjadi 3 (tiga) type, yaitu penelitian penjajakan (eksplorat), penelitian penjelasan (eksplanatory) dan penelitian deskriptif. Penelitian deskriptif yaitu yang berusaha untuk menuturkan pemecahan masalah yang ada sekarang berdasarkan datadata dan bertujuan untuk memecahkan masalah secara sistematis dan factual dari populasi (Masri Singarimbun dan Safi Efendi, 1991:44). 
Dalam penelitian ini, penulis menggunakan rancangan tipe penelitian statistik kuantitatif, sebab penulis membuat analisis perhitungan berdasarkan data yang ada dan mendeskripsikannya secara sistematis, factual dan akurat mengenai fakta-fakta, sifat-sifat serta hubungan antar fenomena yang diselidiki dengan tidak mengesampingkan bahwa peneliti akan membuktikan hipotesis yang telah dirumuskana sebelumnya.

\section{HASIL DAN PEMBAHASAN}

Dari hasil pengamatan dari responden, dapat ditampilkan hasilnya secara lengkap berkaitan dengan pengukuran Indeks Kepuasan Masyarakat (IKM) pada kegiatan pelayanan Pemerintah Desa Kadudampit Kecamatan Saketi Kabuapten Pandeglang.

Pengumpulan data dalam kajian IKM Kabupaten Pandeglang Tahun 2018 ini dilakukan dengan menyebarkan kuesioner kepada masyarakat pengguna jasa 24 unit pelayanan publik, yang meliputi harapan dan tanggapan/persepsi terhadap kualitas pelayanan. Kinerja 24 unit diukur dari sudut pandang masyarakat pengguna layanan.Jenis layanan tersebut mencakup layanan adminsitrasi 8 unit dan layanan barang dan jasa 16 unit.

Responden dalam kajian IKM ini berkisar 15 sampai 40 orang, yakni anggota masyarakat Kabupaten Pandeglang yang pernah menerima layanan yang diberikan oleh aparat pemerintah dari unit layanan yang telah ditentukan. Pemilihan responden dilakukan dengan metode simple random sampling, sampling jenuh dan aksidental.

Berdasarkan hasil perhitungan maka masing-masing unsur pada Pemerintah Desa Kadudampit Kecamatan Saketi Kabuapten Pandeglang dapat di analisi sebagai berikut :

\section{Unsur Prosedur Pelayanan}

Mengenai unsur 1 yaitu prosedur pelayanan, dari hasil penelitian ini terlihat bahwa masyarakat masih menilai bahwa prosedur pelayanan pada Pemerintah Desa Kadudampit Kecamatan Saketi Kabuapten Pandeglang adalah masih kurang Baik (kurus) (skor $=2.76$ ). unsur ini dijabarkan dalam beberapa pertanyaan memiliki hubungan yang erat satu sama lain dalam hal ini mencakup kemudahan dan kesederhanaan dalam melakukan pengurusan perizinan.

Walaupun unsur 1 mendapatkan point baik, nampaknya perlu ditingkatkan kembali dan dipikirkan masalah-masalah teknis yang lebih dapat mengefektifkan informasi mengenai 
"apa dan siapa" petugas yang sedang dihadapi atau harus ditemui oleh masyarakat dalam pengurusan di Pemerintah Desa Kadudampit Kecamatan Saketi Kabuapten Pandeglang.

\section{Unsur Persyaratan Pelayanan}

Mengenai Unsur 2 yaitu persyaratan pelayanan, dari hasil penelitian ini terlihat bahwa masyarakat menilai bahwa persyaratan pelayanan pada Pemerintah Desa Kadudampit Kecamatan Saketi Kabuapten Pandeglang. baik (Skor = 3.00.) unsur ini dijabrkan dalam beberapa pertanyaan yang memiliki hubungan erat satu sama lain dalam hal ini mencangkup kemudahaan persyaratan dan kesederhanaan persyaratan perizinan dalam melakukan kepengurusan izin. Berkaitan dengan hal tersebut, walaupun masyarakat menilai sudah baik, nampaknya perlu dipikirkan dan dipertahankan agar kinerja persyaratan pelayanan untuk ditingkatkan dimasa yang akan dating, agar masyarakat merasa dalam pengurusan perizinan di Pemerintah Desa Kadudampit Kecamatan Saketi Kabuapten Pandeglang merasa puas dan nyaman.

\section{Unsur Kejelasan Petugas Pelayanan}

Unsur in merupakan unsur 3 yang harus dipenuhi dalam kegiatan pelayanan pada instansi publik. Nama jabatan serta kewenangan dan tanggung jawab petugas pelayanan, seharusnya diketahui secara jelas oleh masyarakat yang mengurus izin di Pemerintah Desa Kadudampit Kecamatan Saketi Kabuapten Pandeglang. Unsur ketiga ini dinilai baik (Skor $=2.90$ ) oleh responden. Unsur ini dijabarkan pada beberapa pertanyaan antara lain berkaitan dengan tanda pengenal, nama petugas dan jabatanya. Dari hasil pengumpulan data dapat dijelaskan bahwa masyarakat banyak yang tidak tahu nama petugas dan jabatanya. Berkaitan dengan hal tersebut, nampaknya perlu dipikirkan masalah-masalah teknis yang mengefektifkan informasi mengenai apa dan siapa petugas yang sedang dihadapi atau harus ditemui oeh masyarakat dalam mengurus izin .

\section{Unsur Kedisiplinan Petugas Dalam Melakukan Pelayanan Terhadap Masyarakat}

Kesungguhan petugas didalam melakukan pelayanan terhadap masyarakat, terlihat anata lain dari kesungguhan dalam melayani masyarakat dengan memperhatikan konsistensi waktu kerja. Dalam hal ini disebut sebagai unsur kedisiplinan petugas pelayanan. Untuk 
unsur yang menyangkut prilaku kerja petugas pelayanan responden memberikan penilaian baik (kurus) (Skor $=2.86$ ) hal ini memberikan kesan kurang baik perlu ditingkatkan bahwa masyarakat menilai dan melihat para petugas di Pemerintah Desa Kadudampit Kecamatan Saketi Kabupaten Pandeglang belum memenuhi waktu kerja dan kedisiplinan belum dilakukan secara konsisten.

\section{Unsur Tanggung Jawab Petugas Pelayanan}

Berkaitan dengan unsur ke 5 diatas, terkait dengan unsur selanjutnya (unsur ke 5) yaitu tanggung jawab petugas pelayanan. Kedisiplinan, merupakan manifestasi dari sikap tanggung jawab petugas dan kewenangannya dalam penyelenggaraan dan penyelesaian pelayanan. Unsur tanggung jawab petugas pelayanan menurut penilaian masyarakat sudah baik terbukti dengan $($ Skor $=3.02)$.

Apa yang menjadi tanggung jawab dan kewenangan petugas pelayanan sudah semestinya untuk dijalankan secara professional. Pemahaman terhadap kewenangan dan tanggung jawab petugas terhadap pekerjaan memang modal untuk mewujudkan pelayanan yang memebrikan kepuasan tehadap masyarakat.

\section{Unsur Kemampuan Petugas Pelayanan}

Sebagai unsur 6 kemapuan petugas pelayanan sudah baik dinilai oleh responden. Dalam penelitian ini terlihat bahwa baik (Skor $=3.06$ ). hal ini berarti bahwa masyarakat sudah merasa tingkat kemampuan, keahlian dan keterampilan yang ditampilkan oleh petugas pelayanan dalam memberikan pelayanan kepada masyarakat dirasakan sudah baik.

\section{Unsur Kecapatan Pelayanan}

Sebagai salah satu indicator pelayanan Prima, adalah kecepatan pelayanan unsur ke-7 ini masyarakat menilai kecepatan pelayanan dari sisi target waktu penyelesaian pelayanan dari hasil pengumpulan data dan informasi dilapangan responden memberi nilai atau (Skor $=$ 2.64) baik (kurus) skor tersebut mengambarkan penialian yang kurang baik. Masyarakat menilai bahwa petugas pelayanan belum bias mencapai target waktu sebagaimana ditentukan oleh Pemerintah Desa Kadudampit Kecamatan Saketi Kabupaten Pandeglang.

\section{Unsur Keadilan Mendapatkan Pelayanan}


Masyarakat mempunyai hak untuk memperoleh kualitas pelayanan yang sama. Oleh karena itu, unsur keadilan mendapatkan pelayanan merupakan salah satu indicator yang digunakan dalam mengukur indeks kepauasan masyarakat. hasil yang diperoleh pada unsur keadilan berada pada Skor = 3.06) Baik skor tersebut mengindikasikan bahwa masyarakat sudah merasa dalam memberikan pelayanan merasa puas terhadap keadilan petugas dalam memberikan pelayanan.

\section{Unsur Kesopanan Dan Keramahan Petugas Pelayanan}

Setiap individu atau masyarakat menginginkan untuk diterima dengan penerimaan tulus dan ikhlas yang mucul dalam sikap ramah dan sopan . kesopanan dan keramahaan petugas pelayanan, juga menggambarkan penghargaan terhadap masyarakat yang harus dilayaninya. Responden dalam hal ini sudah merasa dilayani dengan sopan dan ramah oleh petugas pelayanan di Pemerintah Desa Kadudampit Kecamatan Saketi Kabupaten Pandeglang karena responden menilai unsur ke 9 ini dengan $($ Skor $=3.06)$ baik sesuai dengan Motto yang ada di Pemerintah Desa Kadudampit Kecamatan Saketi Kabupaten Pandeglang

“Ramah dan Bersahabat" (Salam, Sapa, Sopan, Santun, Ramah, Someah, Akrab).

\section{Unsur Kewajaran Biaya Kewajaran biaya pelayanan}

menyangkut ke keterjangkauan masyarakat terhadap besarnya biaya yang ditetapkan oleh Pemerintah Desa Kadudampit Kecamatan Saketi Kabupaten Pandeglang Kabupaten Pandeglang. Mengenai Biaya responden masih menganggap bahwa untuk unsur ke 10 ini mereka menilai wajar dan baik (Skor $=3.00)$ artinya responden sudah memamahami dengan baik mengenai besaran biaya yang ditetapkan.

\section{Unsur Kepastian Biaya}

Hal yang cukup baik adalah adanya anggapan bahwa masyarakat menilai dari unsur biaya yang dipungut atau dibayar oleh masyarakat sudah sesuai yang ditetapkan hal ini terbukti responden menilai Baik dengan $(S k o r=3.00)$ Baik.

\section{Unsur Kepastian Jadwal Pelayanan}

Hal yang menjadi salah satu tolak ukur keberhasilan pelayanan adalah bukan hanya pelayanan cepat, mungkin lebih dari itu adalah kepastian jadwal. Cepat atau memekan 
waktu, dapat diterima apabila ada kepastian. Dalam hal ini responden nampaknya menilai mutu pelayanan dalam hal ketepatan atau kepastian jadwal kurang baik (Skor $=2.54)$ Baik (Kurus) dan nampaknya Skor Paling Rendah.

\section{Unsur Kenyamanan Lingkungan Pelayanan}

Meskipun tidak terkait langsung dengan kegiatan masyarakat dalam mengurus perizinan, akan tetapi lingkungan pelayanan tempat dimana masyarakat datang untuk menjalankan kegaiatan tersebut, mempunyai pengaruh yang relevan. Kenyamanan lingkungan menyangkut kebersihan, kerapian dan keteraturan sarana dan prasaran yang ada, memberikan situasi psikologis yang positif. Keahrusan dalam mengurus perizinan, tidak dirasakan sekedar sebagian beban yang membosankan, tetapi juga mempunyai nilai keratifitas yang memebrikan rasa tenang dan puas. Untuk unsur ini responden memberikan (skor =2.82) Baik (Kurus) dengan demikian unsur tesebut belum memenuhi standar Kepusan Masyarakat.

\section{Unsur Keamanan Lingkungan Pelayanan}

Tingkat Kemanan Lingkungan unit penyelenggara perizinan, juga keandalan dari sarana yang digunakan, diharapkan juga memenuhi harapan masyarakat, unsur keamanan lingkungan pelayanan memperoleh nilai dari responden/masyarakat baik dengan (Skor = 3.00). Dari ke 14 unsur pelayanan yang di analisis secara keseluruhan dari hasil survey responden memebrikan hasil yang menunjukan bahwa penilaian masyarakat terhadap Pemerintah Desa Kadudampit Kecamatan Saketi Kabupaten Pandeglang. Secara keseluruhan sudah baik. Hal ini tersebut disimpulkan dari hasil perhitungan indeks Kepuasan Masyarakat $(\mathrm{IKM})=72.278$. Apabila dirujuk pada indek kepuasan masyarakat maka skor yang dicapai melalui penelitian ini , tergolong pada kriteria "Baik".

\section{SIMPULAN}

Berdasarkan uraian di atas dapat disimpulkan kinerja pelayanan di Pemerintah Desa Kadudampit Kecamatan Saketi Kabupaten Pandeglang dan Berdasarkan hasil perhitungan tersebut maka masing-masing unsur pada Pemerintah Desa Kadudampit Kecamatan Saketi Kabupaten Pandeglang dapat di analisi dari 9 unsur yang dianalisi bahwa ada 3 Unsur yang dinilai kinerja unit pelayanan yang dianggap kurang baik oleh responden diantaranya : 
- Persyaratan Pelayanan nilai unsur pelayanannya baik tapi nilai intervalnya kurang.

- Waktu Pelayanan nilai unsur pelayanannya baik tapi nilai intervalnya rendah/kurang.

- Prilaku Pelaksana nilai unsur pelayanannya baik tapi nilai intervalnya rendah/kurang.

- Prosedur Pelayanan nilai unsur pelayanannya baik nilai intervalnya baik dan perlu dipertahankan dan ditingkatkan

- Biaya /tarif nilai unsur pelayanannya baik nilai intervalnya baik dan perlu dipertahankan dan ditingkatkan

- Produk sepesifikasi jenis layanan nilai unsur pelayanannya baik nilai intervalnya baik dan perlu dipertahankan dan ditingkatkan

- Kompetensi Pelaksana nilai unsur pelayanannya baik nilai intervalnya baik dan perlu dipertahankan dan ditingkatkan

- Maklumat Pelayanan nilai unsur pelayanannya baik nilai intervalnya baik dan perlu dipertahankan dan ditingkatkan

Penanganan dan pengaduan nilai unsur pelayanannya baik nilai intervalnya baik dan perlu dipertahankan dan ditingkatkan.

\section{REFERENSI}

Islamy, M. Irfan, (2001)Prinsip-Prinsis Kebijakan Negara, Bumi Akasara, Kajarta Moleong, Lexy J., (2010) Metodologi Penelitian Kualitatif, cetakan ke-27, PT. Remaja Rosdakarya, Bandung

Peraturan Daerah No. 1 Tahun 2010, tentang Urusan Pemerintahan Daerah Kabupaten Pandeglang

Peraturan Daerah No. 2 Tahun 2014 tentang Pembentukan Organisasi Perangkat Daerah Kabupaten Pandeglang

Peraturan Daerah No. 6 Tahun 2011 tentang Penyelenggaraan Administrasi Kependudukan Peraturan Menpan dan Reformasi Birokrasi No. 16 Tahun 2014 tentang Pedoman Survei Kepuasan Masyarakat Terhadap Penyelengaraan Pelayanan Publik

Peraturan Pemerintah No. 96 Tahun 2012 tentang Pelaksanaan Undang-Undang No. 25 Tahun 2009

Sugiyono, (2001) Metode Penelitian Administrasi, Alfa Beta, Bandung Sedarmayanti, (2000), Restrukturisasi dan Pemberdayaan Organisasi, Mandar Majur, Bandung 
Tjiptono, Fandi, (2008) Service Management Mewujudkan Pelayanan Prima, CV. Andi Offset, Yogyakarta

Undang-Undang No. 25 Tahun 2009 tentang Pelayanan Publik

Undang-Undang No. 32 Tahun 2004 tentang Pemerintah Daerah

Wahab, Abdul, (2008) Analisis Kebijakan dari Formulasi ke Implementasi Kebijaksanaan Negara, Bumi Aksara, Jakarta 